\title{
ON RELAXATION PROCESSES IN A COMPLETELY IONIZED PLASMA
}

\author{
(iD)Alexander I. Sokolovsky,*, Dergey A. Sokolovsky ${ }^{\mathrm{b}}$, Dleh A. Hrinishyn ${ }^{\mathrm{a}}$ \\ ${ }^{a}$ Oles Honchar Dnipro National University, Gagarin Ave. 72, Dnipro, Ukraine \\ ${ }^{b}$ Prydniprovska State Academy of Civil Engineering and Architecture, Chernyshevsky Str. 24a, Dnipro, Ukraine \\ *Corresponding Author: alexander.i.sokolovsky@gmail.com \\ Received June 5, 2020; accepted June 30, 2020
}

\begin{abstract}
Relaxation of the electron energy and momentum densities is investigated in spatially uniform states of completely ionized plasma in the presence of small constant and spatially homogeneous external electric field. The plasma is considered in a generalized Lorentz model which contrary to standard one assumes that ions form an equilibrium system. Following to Lorentz it is neglected by electron-electron and ion-ion interactions. The investigation is based on linear kinetic equation obtained by us early from the Landau kinetic equation. Therefore long-range electron-ion Coulomb interaction is consequentially described. The research of the model is based on spectral theory of the collision integral operator. This operator is symmetric and positively defined one. Its eigenvectors are chosen in the form of symmetric irreducible tensors which describe kinetic modes of the system. The corresponding eigenvalues are relaxation coefficients and define the relaxation times of the system. It is established that scalar and vector eigenfunctions describe evolution of electron energy and momentum densities (vector and scalar system modes). By this way in the present paper exact close set of equations for the densities valid for all times is obtained. Further, it is assumed that their relaxation times are much more than relaxation times of all other modes. In this case there exists a characteristic time such, that at corresponding larger times the evolution of the system is reduced described by asymptotic values of the densities. At the reduced description electron distribution function depends on time only through asymptotic densities and they satisfy a closed set of equations. In our previous paper this result was proved in the absence of an external electric field and exact nonequilibrium distribution function was found. Here it is proved that this reduced description takes also place for small homogeneous external electric field. This can be considered as a justification of the Bogolyubov idea of the functional hypothesis for the relaxation processes in the plasma. The proof is done in the first approximation of the perturbation theory in the field. However, its idea is true in all orders in the field. Electron mobility in the plasma, its conductivity and phenomenon of equilibrium temperature difference of electrons and ions are discussed in exact theory and approximately analyzed. With this end in view, following our previous paper, approximate solution of the spectral problem is discussed by the method of truncated expansion of the eigenfunctions in series of the Sonine polynomials. In one-polynomial approximation it is shown that nonequilibrium electron distribution function at the end of relaxation processes can be approximated by the Maxwell distribution function. This result is a justification of the Lorentz-Landau assumption in their theory of nonequilibrium processes in plasma. The temperature and velocity relaxation coefficients were calculated by us early in one- and two-polynomial approximation.
\end{abstract}

KEYWORDS: plasma, generalized Lorentz model, relaxation coefficients, collision integral operator, spectral theory, onepolynomial approximations, functional hypothesis.

\section{INTRODUCTION}

This paper is devoted to the investigation of relaxation processes in completely ionized plasma. It is meant nonequilibrium processes that can be observed in spatially homogenous states of a system. Near the equilibrium they describe the so-called kinetic modes of the considered system. Taking into account relaxation processes in theory of spatially non-uniform states is the next step after their investigation for spatially uniform nonequilibrium states. From a different point of view taking into account relaxation processes is extension of set of parameters that describe nonequilibrium state (reduced description parameters). This is the main trend in theory of nonequilibrium processes. Some important examples are given by the extended irreversible thermodynamics [1], a theory with nonequilibrium correlations of the standard reduced description parameters as additional independent ones (see, for example, [2]), a theory of nonequilibrium states in the vicinity of the standard ones (see, for example, [3]).

In the present paper plasma is considered in the generalized Lorentz model, in which electron-electron interaction is neglected and the ion subsystem is assumed to be an equilibrium ideal gas. In the standard Lorentz model [4] the ion subsystem is a system of hard spheres in the rest. The generalized Lorentz model is based on the Landau kinetic equation [5] (see also in [6]) and, therefore, takes into account peculiarities of the Coulomb interaction. It was introduced in our paper [7]. The same model is discussed in [8] on the base of the Boltzmann kinetic equation.

In plasma states with different component temperatures their relaxation is observed. For the first time the problem of equalizing the electron and ion component temperatures in plasma was investigated by Landau [5] (the component velocity relaxation is considered analogously in [9]). His research was based on the mentioned kinetic equation [5] and shows that temperature relaxation process is slow one because big difference electron and ion masses. In his investigations (see additional examples in [10]) he assumed without proof that the plasma components quickly become equilibrium and are described by the Maxwell distribution functions. This assumption belongs to Lorentz and was introduced by him in his theory of transport phenomena in metals [4]. Fundamental investigation of the plasma hydrodynamics on the same basis belongs to Braginsky [11]. Similar problem for electron-phonon two-component system was discussed by Bogolyubov and Bogolyubov (Jr.) in their research [12] on the polaron theory. They 
considered solution of the kinetic equation for polarons interacting with equilibrium phonon system using the Maxwell distribution with macroscopic velocity as a good approximation for the polaron distribution function.

In fact the mentioned assumption is unfair because the Maxwell distributions for electrons and ions with different temperatures and macroscopic velocities are not solution of kinetic equations for all models of the plasma dynamics. Therefore, the main problem of the theory is to find the main approximation for electron and ion distribution functions of plasma with two component temperatures and velocities. This problem is related to the absence of a small parameter in the theory of relaxation. An approach to solution of this problem was proposed by us with the idea to investigate relaxation processes in the vicinity of standard described nonequilibrium processes (equilibrium states included) [3]. An important example is our investigation of the two-fluid plasma hydrodynamics in the vicinity to one-fluid one [13] (see also a review [14]).

Our previous investigations of nonequilibrium processes in plasma (for example, in $[13-15,16]$ ) are primarily based on the Bogolyubov idea of the functional hypothesis (its consistent and complete discussion see in [6]). According this one plasma component distribution functions $\mathrm{f}_{a p}(x, t)$ ( $a$ is component number) after some characteristic time $\tau_{0}$ depend on time only through the asymptotic values $\xi_{\mu}^{(+)}(x, t)$ of some parameters $\xi_{\mu}(x, t)(\mu$ is parameter number)

$$
\mathrm{f}_{a p}(x, t) \underset{t>>\tau_{0}}{\longrightarrow} \mathrm{f}_{a p}^{(+)}(x, t), \quad \xi_{\mu}(x, t) \underset{t>>\tau_{0}}{\longrightarrow} \xi_{\mu}^{(+)}(x, t), \quad \mathrm{f}_{a p}^{(+)}(x, t)=\mathrm{f}_{a p}\left(x, \xi^{(+)}(t)\right),
$$

which are called the reduced description parameters. Here $\mathrm{f}_{a p}(x, \xi)$ is some functional of the functions $\xi_{\mu}(x)$. Asymptotic distribution function $\mathrm{f}_{a p}^{(+)}(x, t)$ is exact (as well $\left.\mathrm{f}_{a p}(x, t)\right)$ solution of kinetic equation which describes evolution of the plasma. Parameters $\xi_{\mu}^{(+)}(x, t)$ describe states of the plasma and satisfy a closed set of equations of the form

$$
\partial_{t} \xi_{\mu}^{(+)}(x, t)=L_{\mu}\left(x, \xi^{(+)}(t)\right)
$$

where $L_{\mu}(x, \xi)$ is some functionals of the functions $\xi_{\mu}(x)$. The Bogolyubov idea of the functional hypothesis is basis of his method of the reduced description of nonequilibrium systems. In these terms according above discussion the main problem of the relaxation phenomena in plasma investigation is to find the distribution function $\mathrm{f}_{a p}(x, \xi)$ in spatially uniform states.

Contrary to our mentioned papers [13-16], which are based on the Bogolyubov method of the reduced description on nonequilibrium states, the present paper develops kinetics of the system through elaborating the spectral theory of the collision integral operator without assumption that relaxation processes are considered at its completion. This is possible because the plasma is considered in the generalized Lorentz model [7] in which kinetic equation for electrons is a linear one and ions form an equilibrium system. In this approach the relaxation phenomena in plasma are discussed for spatially uniform states in our papers $[17,18]$ and exact distribution function is found in the terms of scalar and vector eigenfunction $A_{p}, B_{p} p_{n}$ of the collision integral operator. These eigenfunction are calculated by the method of truncated expansion in the Sonine polynomial series. The paper [17] discusses this problem for the case of the presence constant small spatially homogeneous external electric field with some simplifying assumptions.

The presented paper provides a consequence investigation of the relaxation processes in plasma at small electric field. Spectral theory of the collision integral operator is discussed in the terms of eigenfunctions that are irreducible tensors.

The paper is constructed as it follows. In the section "Basic equations of the theory" the generalized Lorentz model is formulated following to [7] and basics of spectral theory of the collision integral operator are presented. The section "Evolution of energy and momentum densities of the electron system" discusses dynamics of the densities. The next section "Reduced description of the system by energy and momentum densities" investigates long time evolution of the system and predicts equilibrium state of the system. The section "Approximate calculation of the main quantities of the theory" discusses approximate solution of the spectral problem for the collision integral operator.

\section{BASIC EQUATIONS OF THE THEORY}

This paper is devoted to the study of relaxation processes in spatially homogeneous completely ionized plasma in the presence of small external electric field. The plasma is considered in the generalized Lorentz model in which the ion subsystem is assumed to be in equilibrium and in the state of the macroscopic rest with the temperature $T_{0}$. The model is based on the Landau kinetic equation [5] and was introduced in our paper [7]. The electron kinetic equation of the model has the form

$$
\partial_{t} \mathrm{f}_{p}(t)=-F_{n} \frac{\partial \mathrm{f}_{p}(t)}{\partial p_{n}}+I_{p}\left(\mathrm{f}_{p^{\prime}}(t)\right), \quad\left(F_{n}=-e E_{n}, \quad \int d^{3} p \mathrm{f}_{p}(t)=n\right)
$$


with collision integral given by the formula

$$
I_{p}\left(\mathrm{f}_{p^{\prime}}\right)=\frac{\partial}{\partial p_{n}}\left[D_{n l}(p)\left(\frac{\partial \mathrm{f}_{p}}{\partial p_{l}}+\frac{p_{l}}{m T_{0}} \mathrm{f}_{p}\right)\right]
$$

where function $D_{n l}(p)$ is defined by expressions

$$
D_{n l}(p)=2 \pi e^{4} z^{2} L \int d^{3} p^{\prime} w_{i p^{\prime}} S_{n l}\left(\frac{p}{m}-\frac{p^{\prime}}{M}\right), \quad S_{n l}(u)=\left(u^{2} \delta_{n l}-u_{n} u_{l}\right) / u^{3}
$$

Here $L$ is the Coulomb logarithm, $-e$ is charge of an electron, ze is charge of an ion, $E_{n}$ is homogeneous constant electric field. Hereafter electron and ion equilibrium distribution functions are written as

$$
w_{p} \equiv \frac{n}{\left(2 \pi m T_{0}\right)^{3 / 2}} e^{-\frac{p^{2}}{2 m T_{0}}}, \quad I_{p}\left(w_{p^{\prime}}\right)=0 ; \quad w_{i p} \equiv \frac{n_{0}}{\left(2 \pi M T_{0}\right)^{3 / 2}} e^{-\frac{p^{2}}{2 M T_{0}}}
$$

( $n, n_{0}$ are electron and ion component number of particles densities; $m, M$ are electron and ion masses).

It is convenient to conduct the research of the considered system using the collision integral operator $\hat{K}$ given by the formulas [7]

$$
\hat{K} a_{p}=w_{p}^{-1} I_{p}\left(w_{p^{\prime}} a_{p^{\prime}}\right), \quad \hat{K} a_{p}=-\left(\frac{\partial}{\partial p_{n}}-\frac{p_{n}}{m T_{0}}\right) D_{n l}(p) \frac{\partial a_{p}}{\partial p_{l}}
$$

(hereafter arbitrary real functions are defined by $a_{p}, b_{p}, \ldots$ ). In the term of scalar product

$$
\left(a_{p}, b_{p}\right)=\int d^{3} p w_{p} a_{p} b_{p}=\left\langle a_{p} b_{p}\right\rangle \quad\left(\left\langle a_{p}\right\rangle \equiv \int d^{3} p w_{p} a_{p}\right)
$$

linear operator $\hat{K}$ is a symmetric and positively defined one. Therefore, its eigenfunctions $g_{i p}$ and eigenvalues $\lambda_{i}$

have the properties

$$
\hat{K} g_{i p}=\lambda_{i} g_{i p}
$$

$$
\lambda_{i}>0, \quad\left(g_{i}, g_{i^{\prime}}\right) \equiv b_{i} \delta_{i i^{\prime}}, \quad\left\langle g_{i p}\right\rangle=0
$$

( $b_{i}$ are normalization constants). In this paper eigenfunctions $g_{i p}$ are chosen in the form of symmetric irreducible tensors multiplied by a function of the momentum modulus. The simplest of them are given by expressions

$$
C(p)=A_{p}, \quad C_{l}(p)=B_{p} p_{l}, \quad C_{l m}(p) \equiv C_{p}\left(p_{l} p_{m}-\frac{1}{3} p^{2} \delta_{l m}\right), \ldots C_{l_{1} \ldots l s}(p) \ldots
$$

Convolution of arbitrary two indices of each tensor $C_{l_{1} \ldots l_{s}}(p)(s \geq 2)$ is equal to zero.

Instead of distribution function $\mathrm{f}_{p}$ it is convenient to introduce new one $g_{p}$ and rewrite the kinetic equation (3) in its terms

$$
\mathrm{f}_{p}=w_{p}\left(1+g_{p}\right), \quad \partial_{t} g_{p}=-F_{n} \frac{\partial w_{p}\left(1+g_{p}\right)}{\partial p_{n}} w_{p}^{-1}+\hat{K} g_{p}
$$

to simplify investigation of the small electric field case. Solution of this equation can be sought, following to our paper [17], in the form of a series in eigenfunctions $g_{i p}$ of the operator $\hat{K}$

$$
g_{p}(t)=\sum_{i} c_{i}(t) g_{i p} .
$$


In the absence of the electric field this solution is given by relation

$$
g_{p}^{(0)}(t)=\sum_{i} c_{i 0} g_{i p} e^{-t \lambda_{i}}, \quad \lambda_{i} \equiv 1 / \tau_{i}
$$

where the coefficients $c_{i 0}$ are defined by initial value of the distribution function $\mathrm{f}_{p}(t=0)$. Each term in this formula describes a relaxation (kinetic) mode of the system (hereafter $a^{(0)}$ denotes contribution to a quantity $a$ in the absence of the electric field). Eigenvalues $\lambda_{i}$ are called the relaxation coefficients and define the relaxation times $\tau_{i}$ of the system.

\section{EVOLUTION OF ENERGY AND MOMENTUM DENSITIES OF THE ELECTRON SYSTEM}

In this paper relaxation processes are investigated which related to electron subsystem energy $\varepsilon$ and momentum $\pi_{n}$ densities that are defined by the formulas

$$
\varepsilon \equiv \int d^{3} p \varepsilon_{p} \mathrm{f}_{p}=\left\langle\varepsilon_{p} g_{p}\right\rangle+\varepsilon_{0}, \quad \pi_{l} \equiv \int d^{3} p \mathrm{f}_{p} p_{l}=\left\langle p_{l} g_{p}\right\rangle \quad\left(\varepsilon_{p} \equiv \frac{p^{2}}{2 m}, \varepsilon_{0} \equiv \frac{3}{2} n T_{0}\right) .
$$

In this connection scalar $A_{p}$ and vector $B_{p} p_{n}$ eigenvalues and the corresponding eigenvalues $\lambda_{T}, \lambda_{u}$ are most important

$$
\hat{K} A_{p}=\lambda_{T} A_{p}, \quad \hat{K} B_{p} p_{n}=\lambda_{u} B_{p} p_{n} \quad\left(\left\langle A_{p}\right\rangle=0\right) .
$$

To these relations the normalization conditions should be added which for the further convenience are chosen in the form

$$
\left\langle A_{p} \varepsilon_{p}\right\rangle=3 n / 2, \quad\left\langle B_{p} \varepsilon_{p}\right\rangle=3 n / 2
$$

According to (13), (16) function $g_{p}$ can be written in more concrete form

$$
g_{p}=c_{T} A_{p}+c_{u_{l}} B_{p} p_{l}+\sum_{i \neq T, u_{l}} c_{i} g_{i p}
$$

with understandable notations for the coefficients $c_{i}$. Now expressions (15) for electron energy $\varepsilon$ and momentum $\pi_{n}$ densities give

$$
\pi_{l}=c_{T}\left\langle p_{l} A_{p}\right\rangle+c_{u_{n}}\left\langle p_{l} B_{p} p_{n}\right\rangle+\sum_{i \neq T, u_{l}} c_{i}\left\langle p_{l} g_{i p}\right\rangle, \quad \varepsilon=\varepsilon_{0}+c_{T}\left\langle\varepsilon_{p} A_{p}\right\rangle+c_{u_{n}}\left\langle\varepsilon_{p} B_{p} p_{n}\right\rangle+\sum_{i \neq T, u_{l}} c_{i}\left\langle\varepsilon_{p} g_{i p}\right\rangle
$$

Taking into account the rotational invariance considerations and conditions (17) gives

$$
\pi_{l}=m n c_{u_{l}}, \quad \varepsilon=\varepsilon_{0}+\frac{3 n}{2} c_{T}
$$

because

$$
\left\langle p_{l} g_{i p}\right\rangle=0, \quad\left\langle\varepsilon_{p} g_{i p}\right\rangle=0 \quad(i \neq T, u) .
$$

Note, to explain these identities that tensors $\left\langle p_{l} g_{i p}\right\rangle$ and $\left\langle\varepsilon_{p} g_{i p}\right\rangle$ with $i \neq T, u$ are expressed only through sums of the Kronecker delta of the type $\delta_{n l}$ products. Convolution of arbitrary two indices of each irreducible tensor is equal to zero and therefore averages in (21) are equal to zero.

Let us derive time equations for the densities $\varepsilon, \pi_{n}$. Kinetic equation (3) and definitions (9), (12), (15), (16), (18) after integration by parts give the next time equations for the momentum density $\pi_{l}$

$$
\begin{gathered}
\partial_{t} \pi_{l}=n F_{l}-\left\langle p_{l} \hat{K} g_{p}\right\rangle=n F_{l}-c_{T}\left\langle p_{l} \hat{K} A_{p}\right\rangle-c_{u_{n}}\left\langle p_{l} \hat{K} B_{p} p_{n}\right\rangle+\sum_{i \neq T, u_{l}} c_{i}\left\langle p_{l} \hat{K} g_{i p}\right\rangle= \\
=n F_{l}-c_{T} \lambda_{T}\left\langle p_{l} A_{p}\right\rangle-c_{u_{n}} \lambda_{u}\left\langle p_{l} B_{p} p_{n}\right\rangle+\sum_{i \neq T, u_{l}} c_{i} \lambda_{i}\left\langle p_{l} g_{i p}\right\rangle
\end{gathered}
$$


and for the energy density $\varepsilon$

$$
\begin{gathered}
\partial_{t} \varepsilon=\frac{1}{m} \pi_{l} F_{l}-\left\langle\varepsilon_{p} \hat{K} g_{p}\right\rangle=\frac{1}{m} \pi_{l} F_{l}-c_{T}\left\langle\varepsilon_{p} \hat{K} A_{p}\right\rangle-c_{u_{n}}\left\langle\varepsilon_{p} \hat{K} B_{p} p_{n}\right\rangle+\sum_{i \neq T, u_{l}} c_{i}\left\langle\varepsilon_{p} \hat{K} g_{i p}\right\rangle= \\
=\frac{1}{m} \pi_{l} F_{l}-c_{T} \lambda_{T}\left\langle\varepsilon_{p} A_{p}\right\rangle-c_{u_{n}} \lambda_{u}\left\langle\varepsilon_{p} B_{p} p_{n}\right\rangle+\sum_{i \neq T, u_{l}} c_{i} \lambda_{i}\left\langle\varepsilon_{p} g_{i p}\right\rangle .
\end{gathered}
$$

are obtained. The rotational invariance considerations, formulas (16), (17), expressions (20) and identities (21) give final form of these equations

$$
\partial_{t} \pi_{l}=n F_{l}-\lambda_{u} \pi_{l}, \quad \partial_{t} \varepsilon=\frac{1}{m} \pi_{l} F_{l}-\lambda_{T}\left(\varepsilon-\varepsilon_{0}\right) .
$$

The obtained equations are valid for all times and without assumption that electric field is small.

\section{REDUCED DESCRIPTION STATE OF THE SYSTEM BY ENERGY AND MOMENTUM DENSITIES}

Let us discuss state of the system at long times. Here and in our paper [17] it is assumed that characteristic time $\tau_{0}$ with the property

$$
\tau_{T}, \tau_{u}>\tau_{0}>\tau_{i} \quad(i \neq T, u)
$$

exists. Let us prove that at long times the following relation

$$
g_{p}^{(+)}(t)=g_{p}\left(\varepsilon^{(+)}(t), \pi^{(+)}(t)\right)
$$

is true, where $g_{p}^{(+)}(t), \varepsilon^{(+)}(t), \pi_{l}^{(+)}(t)$ are asymptotic values of the quantities $g_{p}(t), \varepsilon(t), \pi_{l}(t)$ :

$$
\varepsilon(t) \underset{t>>\tau_{0}}{=} \varepsilon^{(+)}(t), \quad \pi_{l}(t) \underset{t>>\tau_{0}}{=} \pi_{l}^{(+)}(t), \quad g_{p}(t) \underset{t>>\tau_{0}}{=} g_{p}^{(+)}(t)
$$

and $g_{p}(\varepsilon, \pi)$ is some function. In the situation described by relations (26), (27) the system would be completely described at $t>>\tau_{0}$ by parameters $\varepsilon^{(+)}(t), \pi_{l}^{(+)}(t)$ because the electron distribution function (12) is expressed at $t>\tau_{0}$ through parameters $\varepsilon^{(+)}(t), \pi_{l}^{(+)}(t)$

$$
\mathrm{f}_{p}(t) \underset{t>\tau_{0}}{=} w_{p}\left[1+g_{p}\left(\varepsilon^{(+)}(t), \pi^{(+)}(t)\right)\right]
$$

Parameters $\varepsilon^{(+)}(t), \pi_{l}^{(+)}(t)$ according to (22) satisfy exact close equations

$$
\partial_{t} \pi_{l}^{(+)}=n F_{l}-\lambda_{u} \pi_{l}^{(+)}, \quad \partial_{t} \varepsilon^{(+)}=\frac{1}{m} \pi_{l} F_{l}-\lambda_{T}\left(\varepsilon^{(+)}-\varepsilon_{0}\right)
$$

According (1), (2), if (26) is true, in the system the reduced description by parameters $\varepsilon^{(+)}(t), \pi_{l}^{(+)}(t)$ is observed and the statement (26) expresses the Bogolyubov idea of the functional hypothesis.

In our paper [17] under assumption (25) it was proved that in the absence of external electric field function $g_{p}(\varepsilon, \pi)$ is given by exact expression

$$
g_{p}^{(0)}(\varepsilon, \pi)=\left(\varepsilon-\varepsilon_{0}\right) A_{p} 2 / 3 n+\pi_{l} B_{p} p_{l} / m n .
$$

In order to investigate possibility of the reduced description in the presence of electric field let us restrict ourselves by small field. Exact electron distribution function is sought in a series in powers of the field $E_{l}$

$$
\mathrm{f}_{p}=w_{p}\left(1+g_{p}\right), \quad g_{p}=g_{p}^{(0)}+g_{p}^{(1)}+O\left(E^{2}\right)
$$




$$
\begin{gathered}
g_{p}^{(0)}=c_{T}^{(0)} A_{p}+c_{u_{l}}^{(0)} B_{p} p_{l}, \quad c_{T}^{(0)} \equiv c e^{-t \lambda_{T}}, \quad c_{u_{l}}^{(0)} \equiv c_{l} e^{-t \lambda_{u}} \\
g_{p}^{(1)}=\sum_{i} c_{i}^{(1)} g_{i p}=c_{T}^{(1)} A_{p}+c_{u_{l}}^{(1)} B_{p} p_{l}+\sum_{i \neq T, u} c_{i}^{(1)} g_{i p}
\end{gathered}
$$

where $c_{T}^{(1)}, c_{u_{l}}^{(1)}, \quad c_{i}^{(1)}$ are functions of time and have to be found. Functions $g_{p}^{(0)}, g_{p}^{(1)}$ according to (12) satisfy equations

$$
\partial_{t} g_{p}^{(0)}=-\hat{K} g_{p}^{(0)}, \quad \partial_{t} g_{p}^{(1)}=-F_{l} \frac{\partial w_{p}\left(1+g_{p}^{(0)}\right)}{\partial p_{l}} w_{p}^{-1}-\hat{K} g_{p}^{(1)}
$$

First of these equations is due to (16), (31) true. The main contribution $g_{p}^{(0)}$ to function $g_{p}$ with arbitrary coefficients $c, c_{l}$ is chosen in the form (31) that is enough for investigation of the system at $t>>\tau_{0}$ because

$$
\lambda_{i}>>\lambda_{T}, \lambda_{u} \quad(i \neq T, u)
$$

(see (14), (25)). The second equation (32) with account for normalization condition (10) give set of equations for functions $c_{i}^{(1)}=\left(g_{p}^{(1)} g_{i p}\right) / b_{i}$ from (31)

$$
\partial_{t} c_{i}^{(1)}=F_{l}\left(a_{i l} e^{-t \lambda_{T}}+b_{i l} e^{-t \lambda_{u}}+c_{i l}\right)-\lambda_{i} c_{i}^{(1)} .
$$

Here according to (31) after integration by parts the time independent coefficients $a_{i l}, b_{i l}, c_{i l}$

$$
\begin{gathered}
-\frac{1}{b_{i}} \int d^{3} p \frac{\partial w_{p}\left(1+g_{p}^{(0)}\right)}{\partial p_{l}} g_{i p}= \\
b_{i} \int d^{3} p w_{p}\left(1+g_{p}^{(0)}\right) \frac{\partial g_{i p}}{\partial p_{l}}=\frac{1}{b_{i}}\left(\left\langle\frac{\partial g_{i p}}{\partial p_{l}}\right\rangle+\left\langle g_{p}^{(0)} \frac{\partial g_{i p}}{\partial p_{l}}\right\rangle\right)= \\
=a_{i l} e^{-t \lambda_{T}}+b_{i l} e^{-t \lambda_{u}}+c_{i l}
\end{gathered}
$$

are introduced (in [17] this expression wrongly assumed to be constant). Solution of equations (34) has the form

$$
c_{i}^{(1)}=c_{i 0}^{(1)} e^{-t \lambda_{i}}+a_{i l} F_{l}\left(e^{-t \lambda_{T}}-e^{-t \lambda_{i}}\right) /\left(\lambda_{i}-\lambda_{T}\right)+b_{i l} F_{l}\left(e^{-t \lambda_{u}}-e^{-t \lambda_{i}}\right) /\left(\lambda_{i}-\lambda_{u}\right)+c_{i l}\left(1-e^{-t \lambda_{i}}\right) / \lambda_{i} .
$$

Initial conditions $c_{i 0}^{(1)} \equiv c_{i}^{(1)}(t=0)$ for $c_{i}^{(1)}$ are not related to the external field and further will be replaced by zero. According to (25), (33) expression (36) gives

$$
\begin{gathered}
c_{i}^{(1)} \underset{t>\tau_{0}}{=} a_{i l} F_{l} e^{-t \lambda_{T}} /\left(\lambda_{i}-\lambda_{T}\right)+b_{i l} F_{l} e^{-t \lambda_{u}} /\left(\lambda_{i}-\lambda_{u}\right)+c_{i l} F_{l} / \lambda_{i} \quad(i \neq T, u), \\
c_{T}^{(1)} \underset{t>>\tau_{0}}{=}-t a_{T l} F_{l}+b_{T l} F_{l}\left(e^{-t \lambda_{u}}-e^{-t \lambda_{T}}\right) /\left(\lambda_{u}-\lambda_{T}\right)+c_{T l} F_{l}\left(1-e^{-t \lambda_{T}}\right) / \lambda_{T}, \\
c_{u_{m}}^{(1)} \underset{t>>\tau_{0}}{=} a_{u_{m} l} F_{l}\left(e^{-t \lambda_{T}}-e^{-t \lambda_{u}}\right) /\left(\lambda_{T}-\lambda_{u}\right)-t b_{u_{m} l} F_{l}+c_{u_{m} l} F_{l}\left(1-e^{-t \lambda_{T}}\right) / \lambda_{u} .
\end{gathered}
$$

Entering here coefficients are defined by (35). The rotational invariance considerations give

$$
\begin{array}{ccc}
a_{i l}=c\left\langle A_{i \neq T} \frac{\partial g_{i p}}{\partial p_{l}}\right\rangle / b_{i}=0, & b_{i l}=c_{i \neq T, u}\left\langle B_{p} p_{m} \frac{\partial g_{i p}}{\partial p_{l}}\right\rangle / b_{i} \neq 0, & c_{i l}=\left\langle\frac{\partial g_{i p}}{\partial \neq T, u}\right\rangle / b_{i}=0 ; \\
a_{T l} \equiv c\left\langle A_{p} \frac{\partial A_{p}}{\partial p_{l}}\right\rangle / b_{T}=0, & b_{T l} \equiv c_{m}\left\langle B_{p} p_{m} \frac{\partial A_{p}}{\partial p_{l}}\right\rangle / b_{T} \neq 0, & c_{T l} \equiv\left\langle\frac{\partial A_{p}}{\partial p_{l}}\right\rangle / b_{T}=0 ; \\
a_{u_{m} l} \equiv c\left\langle A_{p} \frac{\partial B_{p} p_{m}}{\partial p_{l}}\right\rangle / b_{u} \neq 0, & b_{u_{n} l} \equiv c_{m}\left\langle B_{p} p_{m} \frac{\partial B_{p} p_{n}}{\partial p_{l}}\right\rangle / b_{u}=0, & c_{u_{n} l} \equiv\left\langle\frac{\partial B_{p} p_{n}}{\partial p_{l}}\right\rangle / b_{u} \neq 0
\end{array}
$$


(see remark after relations (21)). Therefore, formulas (37) receive the form

$$
\begin{gathered}
c_{i}^{(1)} \underset{t>\tau_{0}}{=} b_{i l} F_{l} e^{-t \lambda_{u}} /\left(\lambda_{i}-\lambda_{u}\right) \quad(i \neq T, u), \quad c_{T}^{(1)} \underset{t>>\tau_{0}}{=} b_{T l} F_{l}\left(e^{-t \lambda_{u}}-e^{-t \lambda_{T}}\right) /\left(\lambda_{u}-\lambda_{T}\right), \\
c_{u_{n}}^{(1)} \underset{t>>\tau_{0}}{=} a_{u_{n} l} F_{l}\left(e^{-t \lambda_{T}}-e^{-t \lambda_{u}}\right) /\left(\lambda_{T}-\lambda_{u}\right)+c_{u_{n} l} F_{l}\left(1-e^{-t \lambda_{T}}\right) / \lambda_{u} .
\end{gathered}
$$

Finally, according to (27), (31) the electron distribution function $g_{p}$ at long times is given by the formulas

$$
\begin{gathered}
g_{p}^{(+)}=c_{T}^{(+)} A_{p}+c_{u_{l}}^{(+)} B_{p} p_{l}+\sum_{i \neq T, u_{l}} c_{i}^{(+)} g_{i p} ; \\
c_{T}^{(+)} \equiv c e^{-t \lambda_{T}}+b_{T l} F_{l}\left(e^{-t \lambda_{u}}-e^{-t \lambda_{T}}\right) /\left(\lambda_{u}-\lambda_{T}\right), \quad c_{i}^{(+)} \equiv b_{i l} F_{l} e^{-t \lambda_{u}} /\left(\lambda_{i}-\lambda_{u}\right), \\
c_{u_{n}}^{(+)} \equiv c_{n} e^{-t \lambda_{u}}+a_{u_{n} l} F_{l}\left(e^{-t \lambda_{T}}-e^{-t \lambda_{u}}\right) /\left(\lambda_{T}-\lambda_{u}\right)+c_{u_{n} l} F_{l}\left(1-e^{-t \lambda_{T}}\right) / \lambda_{u}
\end{gathered}
$$

with the accuracy up to the first order in the electric field contributions included. It is interesting to note that here secular terms grooving with the time are absents. Relations (37) show that without identities (38) they may be present.

Asymptotic distribution function $g_{p}^{(+)}$according (20), (40) takes the form

$$
g_{p}^{(+)}=\frac{2}{3 n}\left(\varepsilon^{(+)}-\varepsilon_{0}\right) A_{p}+\frac{1}{m n} \pi_{l}^{(+)} B_{p} p_{l}+\sum_{i \neq T, u_{l}} c_{i}^{(+)} g_{i p}
$$

Also due to (20), (40) asymptotic values of energy and momentum densities are written as

$$
\begin{gathered}
\frac{2}{3 n}\left(\varepsilon^{(+)}-\varepsilon_{0}\right)=c e^{-t \lambda_{T}}+b_{T l} F_{l}\left(e^{-t \lambda_{u}}-e^{-t \lambda_{T}}\right) /\left(\lambda_{u}-\lambda_{T}\right), \\
\frac{1}{m n} \pi_{n}^{(+)}=c_{n} e^{-t \lambda_{u}}+a_{u_{n} l} F_{l}\left(e^{-t \lambda_{T}}-e^{-t \lambda_{u}}\right) /\left(\lambda_{T}-\lambda_{u}\right)+c_{u_{n}} F_{l}\left(1-e^{-t \lambda_{T}}\right) / \lambda_{u} .
\end{gathered}
$$

These formulas can be considered as a set of equations for functions $e^{-t \lambda_{T}}, e^{-t \lambda_{u}}$. These equations are obtained here in the first in the electric field approximation. However, in all approximations relations of this type can by used to express functions $e^{-t \lambda_{T}}, e^{-t \lambda_{u}}$ through asymptotic densities $\varepsilon^{(+)}, \pi_{l}^{(+)}$. In all approximations in the field coefficients $c_{i}^{(+)}(i \neq T, u)$ are expressed through exponents $e^{-t \lambda_{T}}, e^{-t \lambda_{u}}$ and, therefore, always they expressed through densities $\varepsilon^{(+)}, \pi_{l}^{(+)}$. So, in all in the field approximations distribution function $g_{p}^{(+)}$is a function of $\varepsilon^{(+)}, \pi_{l}^{(+)}$.

In our case $e^{-t \lambda_{u}}$ as a function of $\varepsilon^{(+)}, \pi_{l}^{(+)}$should be substituted in expression for $c_{i}^{(+)}$given by (40) and calculated in the main approximation in electric field. Therefore, quantity $e^{-t \lambda_{u}}$ as a function of $\varepsilon^{(+)}, \pi_{l}^{(+)}$should be found from (42) only at $F_{n}=0$ that gives

$$
e^{-t \lambda_{u}}=\frac{c_{n}}{c^{2} m n} \pi_{n}^{(+)}, \quad c_{i}^{(+)}=F_{l} \pi_{n}^{(+)} \frac{b_{i l} c_{n}}{c^{2} m n\left(\lambda_{i}-\lambda_{u}\right)} \quad\left(c^{2} \equiv c_{n} c_{n}\right)
$$

So, asymptotic electron distribution function $g_{p}(\varepsilon, \pi)$ according (26), (40), (43) has the form

$$
g_{p}(\varepsilon, \pi)=\frac{2}{3 n}\left(\varepsilon-\varepsilon_{0}\right) A_{p}+\frac{1}{m n} \pi_{n}\left[B_{p} p_{n}+F_{l} \frac{c_{n}}{c^{2}} \sum_{i \neq T, u_{l}} g_{i p} \frac{b_{i l}}{\lambda_{i}-\lambda_{u}}\right] .
$$

In the method of reduced description, elaborated by Bogolyubov, this result with definitions (26), (27) expresses his idea of the functional hypothesis (see general definitions in (1), (2)). It means: after some time $\tau_{0}$ distribution function $g_{p}(t)$ depends on time $t$ only trough asymptotic values $\varepsilon^{(+)}(t), \pi_{l}^{(+)}(t)$ of parameters $\varepsilon(t), \pi_{l}(t)$ and the 
quantities $\varepsilon^{(+)}(t), \pi_{l}^{(+)}(t)$ satisfy closed set of equations (31). Therefore, in this paper the functional hypothesis is proved in the presence of small electric field. For the case of the absence of the field it was proved in our paper [17].

Reduced description of the system by average densities $\varepsilon^{(+)}(t), \pi_{n}^{(+)}(t)$ can be discussed in the terms of electron component temperature $T(t)$ and macroscopic velocity $u_{n}(t)$ defined by formulas

$$
\varepsilon^{(+)}=\left(3 n T+m n u^{2}\right) / 2, \quad \pi_{n}^{(+)}=m n u_{n} .
$$

Exact evolution equations (29) gives exact nonlinear dynamic equations describing the system by variables $T$ and $u_{n}$

$$
\partial_{t} u_{n}=-\lambda_{u} u_{n}+\frac{1}{m} F_{n}, \quad \partial_{t} T=-\lambda_{T}\left(T-T_{0}\right)+\left(2 \lambda_{u}-\lambda_{T}\right) m u^{2} / 3
$$

the second of which does not contain the field. The Cauchy problem for these equations can be easily solved. Equilibrium state of the system is described by relations

$$
\begin{gathered}
u_{n}(t) \underset{t>>\tau_{T}, \tau_{u}}{=} u_{n}^{e q}, \quad u_{n}^{e q}=-v E_{n}, \quad v \equiv \frac{e}{m \lambda_{u}} ; \\
T(t) \underset{t>>\tau_{T}, \tau_{u}}{=} T^{e q}, \quad T^{e q}=T_{0}+\Delta T, \quad \Delta T \equiv \frac{e^{2}\left(2 \lambda_{u}-\lambda_{T}\right)}{3 m \lambda_{T} \lambda_{u}^{2}} E^{2}
\end{gathered}
$$

$\left(F_{n}=-e E_{n}\right)$. Of course, equilibrium quantities $u_{n}^{e q}, T^{e q}$ coincide with ones $u_{n}^{s t}, T^{s t}$ in the steady state of the system. Coefficient $v$ is called the electron mobility and the developed here theory gives an exact expression for him. Our theory predicts difference $\Delta T$ of equilibrium electron and ion temperatures in the presence of external electric field which also is an exact result.

\section{APPROXIMATE CALCULATION OF THE MAIN QUANTITIES OF THE THEORY}

Obtained results show that the main next problem is solving of the spectral problem for the collision integral operator $\hat{K}$. In our paper [17] calculation of the eigenfunctions $A_{p}, B_{p} p_{n}$ and corresponding eigenvalues $\lambda_{T}, \lambda_{u}$ from equations (16), (17) is proposed to conduct by the method of truncated expansion in the Sonine polynomials $S_{q}^{\alpha}(x)(q=0,1,2, \ldots, \alpha$ is a real number $)$

$$
A_{p}=\sum_{q=0}^{\infty} a_{q} S_{q}^{1 / 2}\left(\beta \varepsilon_{p}\right), \quad B_{p}=\sum_{q=0}^{\infty} b_{q} S_{q}^{3 / 2}\left(\beta \varepsilon_{p}\right) \quad\left(\beta \equiv T_{0}^{-1}\right) .
$$

An example of this approach is given in our paper [19], where relaxation processes in polaron subsystem of semiconductors are investigated on the basis of equations (16), (17) but with different operator $\hat{K}$ and with functions $A_{p}, B_{p} p_{n}$, which describe relaxation processes close to the equilibrium. The choice of polynomials is suggested by normalization condition

$$
\left\langle\varepsilon_{p}^{\alpha-1 / 2} S_{q}^{\alpha}\left(\beta \varepsilon_{p}\right) S_{q^{\prime}}^{\alpha}\left(\beta \varepsilon_{p}\right)\right\rangle=\frac{n}{\beta^{\alpha-1 / 2}} \frac{2 \Gamma(q+\alpha+1)}{\pi^{1 / 2} q !} \delta_{q q^{\prime}}
$$

which contains the average with the electron Maxwell distribution $w_{p}$ (4). Formulas (48), (49) and normalization conditions (17) give first coefficients in expansions (48)

$$
a_{0}=0, \quad a_{1}=-\beta, \quad b_{0}=\beta .
$$

In the $s$-polynomial approximation it is assumed that only $s$ coefficients in (48) are not equal to zero. The convergence rate of this procedure cannot be estimated because the considered spectral problem does not related to a small parameter.

The further calculations are similar to ones in quantum-mechanical perturbation theory. Equations (16) take the form

$$
\sum_{q^{\prime}=1}^{\infty} A_{q q^{\prime}} a_{q^{\prime}}=\lambda_{T} a_{q} x_{q}, \quad \quad \sum_{q^{\prime}=0}^{\infty} B_{q q^{\prime}} b_{q^{\prime}}=\lambda_{u} b_{q} y_{q}
$$


where $A_{q q^{\prime}}, B_{q q^{\prime}}$ are matrix elements of the collision integral operator $\hat{K}$ and some coefficients $x_{q}, y_{q}$

$$
\begin{array}{cc}
A_{q q^{\prime}}=\left\{S_{q}^{1 / 2}\left(\beta \varepsilon_{p}\right), S_{q^{\prime}}^{1 / 2}\left(\beta \varepsilon_{p}\right)\right\}, & B_{q q^{\prime}}=\left\{p_{l} S_{q}^{3 / 2}\left(\beta \varepsilon_{p}\right), p_{l} S_{q^{\prime}}^{3 / 2}\left(\beta \varepsilon_{p}\right)\right\} ; \\
x_{q} \equiv 2 n \frac{\Gamma(q+3 / 2)}{\pi^{1 / 2} q !}, & y_{q} \equiv \frac{4 m n}{\beta} \frac{\Gamma(q+5 / 2)}{\pi^{1 / 2} q !}
\end{array}
$$

are introduced. Here standard in kinetic theory notation for the matrix elements of the operator $\hat{K}$ is used and related quantities are called the integral brackets

$$
\left\{a_{p}, b_{p}\right\}=\left\langle a_{p} \hat{K} b_{p}\right\rangle
$$

(according to (8) $\left\langle a_{p} b_{p}\right\rangle$ is the scalar product of functions $a_{p}, b_{p}$ ).

In one-polynomial approximation relations (50) - (52) give [7]

$$
A_{p}^{[1]}=-\beta\left(\frac{3}{2}-\beta \varepsilon_{p}\right), \quad \lambda_{T}^{[1]}=\frac{2 \beta^{2}}{3 n}\left\{\varepsilon_{p}, \varepsilon_{p}\right\} ; \quad B_{p}^{[1]}=\beta, \quad \lambda_{u}^{[1]}=\frac{\beta}{3 m n}\left\{p_{l}, p_{l}\right\}
$$

(a quantity $a$ in s-polynomial approximation is denoted by $a^{[s]}$ ). Entering here brackets can be calculated exactly [7]

$$
\lambda_{u}^{[1]}=\frac{2^{5 / 2} \pi^{1 / 2} e^{4} z^{2} L n_{0}}{3\left(1+\mu^{2}\right)^{1 / 2} m^{1 / 2} T_{0}^{3 / 2}}, \quad \lambda_{T}^{[1]}=\frac{2^{7 / 2} \pi^{1 / 2} \mu^{2} e^{4} z^{2} L n_{0}}{3\left(1+\mu^{2}\right)^{3 / 2} m^{1 / 2} T_{0}^{3 / 2}}=\frac{2 \mu^{2}}{1+\mu^{2}} \lambda_{u}^{[1]} \quad\left(\mu \equiv(m / M)^{1 / 2}\right)
$$

In paper [13] these values were calculated in the main approximation in the parameter $\mu$ which is a small one because

$$
\mu \leq\left(m_{e} / m_{p}\right)^{1 / 2} \approx 2,34 \cdot 10^{-2}
$$

(here $m_{e}, m_{p}$ are electron and proton masses). As a result our expression for $\lambda_{u}$ coincides with one from [13] but our expression for $\lambda_{T}$ gives one from [13] after the replacement $n_{0} \rightarrow n_{0}(z+1)$. This result is expected because in [13] the dynamics of ions was more fully taken into account.

Starting from Landau investigation on the temperature relaxation in the completely ionized plasma [5] it is assumed that electron distribution function in spatially uniform states coincides in the main approximation with the Maxwell one (analogous assumption is made in the velocity relaxation theory [9]). In the terms of our consideration it is confirmed only in one-polynomial approximation at small temperature difference $T-T_{0}$ and small velocity $u_{n}$. Really, according to (4), (50) the Maxwell distribution for electron system with temperature $T$ and macroscopic velocity $u_{n}$ can be rewritten as

$$
\begin{gathered}
\left.w_{p-m u}\right|_{T_{0} \rightarrow T}=w_{p}\left[1+\frac{1}{T_{0}}\left(\frac{\varepsilon_{p}}{T_{0}}-\frac{3}{2}\right)\left(T-T_{0}\right)+\frac{1}{T_{0}} p_{n} u_{n}+\ldots\right]=w_{p}\left[1+A_{p}^{[1]}\left(T-T_{0}\right)+B_{p}^{[1]} p_{n} u_{u}+\ldots\right]= \\
=w_{p}\left[1+\frac{2}{3 n} A_{p}^{[1]}\left(\varepsilon-\varepsilon_{0}\right)+\frac{1}{m n} B_{p}^{[1]} p_{n} \pi_{u}+\ldots\right]
\end{gathered}
$$

This expression should be compared with nonequilibrium distribution function given by formulas (12), (30). This remark shows, why Landau relaxation theory [5] gives relaxation coefficient $\lambda_{T}$ which coincides with one in onepolynomial approximation $\lambda_{T}^{[1]}$ from (55) taken in the small $\mu$ limit.

Our general expression (47) for the mobility of electron in plasma can be concretize in one-polynomial approximation with the velocity relaxation coefficient $\lambda_{u}$ from (55) that in the main in small $\mu$ approximation gives

$$
v=\frac{3 T_{0}^{3 / 2}}{2^{5 / 2} \pi^{1 / 2} e^{3} m^{1 / 2} z^{2} L n_{0}},
$$

Electron mobility defines electron current $j_{l}$ of the plasma in the steady state 


$$
j_{l}=-n e u_{l}, \quad u_{l}^{s t}=-v E_{l}
$$

and therefore gives the plasma conductivity $\sigma$

$$
j_{l}^{s t}=\sigma E_{l}, \quad \sigma=e n v=\frac{e^{2} n}{\lambda_{u}}
$$

(see (47)). This formula for $\sigma$ is exact one. It in the one-polynomial approximation and in the main order in the parameter $\mu$ according to expression (58) gives

$$
\sigma=\frac{3 T_{0}^{3 / 2}}{2^{5 / 2} \pi^{1 / 2} e^{2} m^{1 / 2} z L}
$$

Here the plasma neutrality condition $n_{0} z=n$ is taken into account ( $n, n_{0}$ are electron and ion component densities). Note, that this formula differs by numerical coefficient from one obtained for the Lorentz plasma in [10] where approximate expression for the collision integral of the form

$$
I_{p}(\mathrm{f})=-v(p) \delta \mathrm{f}_{p}, \quad v(p) \equiv \frac{4 \pi z e^{4} n m L}{p^{3}} \quad\left(\mathrm{f}_{p} \equiv w_{p}+\delta \mathrm{f}_{p}, I_{p}(w)=0\right)
$$

is used.

Our formula (47) gives exact expression for the electron and ion component temperature difference in equilibrium or steady state of the plasma. In one-polynomial approximation (55) for relaxation coefficients $\lambda_{T}, \lambda_{u}$ it can be expressed through the electron mobility $v$ by the formula

$$
\Delta T=\frac{m v^{2}}{3} E^{2}
$$

This formula was derived also in [8] but without control of its accuracy.

\section{DISCUSSION}

In the present paper the investigation of completely ionized plasma based on our generalization of the Lorentz model is conducted in the presence of constant and spatially uniform electric field. The generalization is based on the Landau kinetic equation and takes into account features of the Coulomb interaction. Contrary to Lorentz it is assumed that ions form equilibrium system. Kinetic equation for the model is linear one and for investigation of nonequilibrium processes a spectral theory of the collision integral operator is used. This operator is rotationally invariant, symmetric and positively defined one. Therefore quantum-mechanical approaches for approximate investigation of nonequilibrium processes in the system are applied here. Eigenfunctions of the collision integral operator describe kinetic modes of the system. In the paper irreducible symmetric tensors as eigenfunction of this operator are used. This very simplifies using rotationally invariance ideas in the calculations. On this base it is proved that energy and momentum densities of the electrons $\varepsilon, \pi_{n}$ are described only by scalar $A_{p}$ and vector $B_{p} p_{n}$ eigenfunctions correspondently. Moreover, this allows proving that for the mentioned densities exact closed linear evolution equations are valid which are true for all times.

Relaxation processes in the electron component can be described instead of densities $\varepsilon, \pi_{n}$ by corresponding temperature $T$ and macroscopic velocity $u_{n}$. The obtained exact evolution equation for the velocity is a linear one but exact evolution equation for the temperature is quadratic in the velocity. These equations contain the temperature and velocity relaxation coefficients $\lambda_{T}, \lambda_{u}$ as eigenvalues of the collision integral operator corresponding to eigenfunctions $A_{p}, B_{p} p_{n}$. In these terms steady (equilibrium) states of the system are discussed and exact expressions for the electron mobility and conductivity are obtained. The equilibrium phenomenon of electron $T$ and ion $T_{0}$ temperature difference is predicted and is described by an exact expression. This effect was discussed in the literature early [8] but with an indefinite accuracy.

Important part of the paper discusses long time behavior of the plasma in the presence of a small constant and spatially uniform electric field. A characteristic time $\tau_{0}$ is introduced so, that at $t>>\tau_{0}$ only vector and scalar modes of the system evolve. The mentioned exact relaxation equations are also true for the asymptotic values $\varepsilon^{(+)}, \pi_{n}^{(+)}$of the quantities $\varepsilon, \pi_{n}$. At these times electron distribution function is investigated. In the straightforward perturbation theory 
in electric field it is shown that this function at $t>>\tau_{0}$ (asymptotic distribution function) depends on time only through the quantities $\varepsilon^{(+)}, \pi_{n}^{(+)}$. This result expresses the Bogolyubov idea of the functional hypothesis that is basis of his method of reduced description of nonequilibrium states.

Further discussion of relaxation phenomena in the system needs of approximate expressions for the relaxation coefficients as eigenvalues of the collision integral operator and corresponding eigenfunctions. However, the related spectral problem can be solved only approximately. With this end in view in the paper the method of truncated expansion in the Sonine polynomials is used. As a result, relaxation coefficients are written in the one-polynomial approximation but exactly in small electron-to-ion mass ratio $\mu^{2}$. Details of these calculations with consideration of the two-polynomial approximation are discussed in our paper [18]. These results show that commonly used the Maxwell distribution function with electron component temperature and velocity as the electron distribution function in the presence of relaxation processes (see $[5,9,10,12])$ is true only in one-polynomial approximation and for small $u_{n}$ and $T-T_{0}$. This explains why our temperature relaxation coefficient $\lambda_{T}$ in one-polynomial approximation coincides with the Landau one [5].

On the base of the obtained here results spatially nonuniform states of plasma in the presence of relaxation processes will be investigated in a subsequent paper.

Note finally, that developed here theory can be applied for investigation of relaxation phenomena in theory of polarons in the Fröhlich model (see, for example, [12]).

\section{ORCID IDs}

DAlexander I. Sokolovsky, https://orcid.org/0000-0001-7988-6753; DSergey A. Sokolovsky, https://orcid.org/0000-0001-6772-647X

DOleh A. Hrinishyn, https://orcid.org/0000-0002-5620-3523

\section{REFERENCES}

[1] D. Jou, J. Casas-Vazques, and G. Lebon, Extended Irreversible Thermodynamics, (Springer, 2010).

[2] S.V. Peletminskii, Yu.V. Slyusarenko, and A.I. Sokolovsky, Physica A. 326(3-4), 412-429 (2003), https://doi.org/10.1016/S0378-4371(03)00255-3.

[3] V.N. Gorev, A.I. Sokolovsky, in: Actual Problems of Mathematical Physics and its Applications. Proceedings of Institute of Mathematics NASU, 11(1), (IM, Kyiv, 2014), pp. 67-92.

[4] H.A. Lorentz, Proc. Acad. Sci. Amsterdam, 7, 438, 585 (1905).

[5] L.D. Landau, ZhETF, 7, 203-209 (1936). (in Russian).

[6] A.I. Akhiezer, S.V. Peletminsky, Methods of Statistical Physics, (Pergamon Press, Oxford, 1981).

[7] S.A. Sokolovsky, A.I. Sokolovsky, I.S. Kravchuk, and O.A. Grinishin, Journal of Physics and Electronics, 26(2), 17-28 (2018), https://doi.org/10.15421/331818.

[8] B.M. Smirnov, UFN, 172(12), 1411-1445 (2002). (in Russian).

[9] A.F. Aleksandrov, L.S. Bogdankevich, and A.A. Rukhadze, Principles of Plasma Electrodynamics, (URSS, Moscow, 2013), pp. 504.

[10] E.M. Lifshitz, and L.P. Pitaevskii, Physical kinetics, (Pergamon Press, Oxford, 1981).

[11] I.S. Braginsky, ZhETF, 33, 459 (1957).

[12] N.N. Bogolyubov, and N.N. Bogolyubov (Jr.), Аспекты теории полярона [Aspects of polaron theory], (Fizmatlit, Moscow, 2004), pp. 175. (in Russian).

[13] V.N. Gorev, and A.I. Sokolovsky, Ukr. J. Phys. 60(3), 232-246 (2015), https://doi.org/10.15407/ujpe60.03.0232.

[14] V. N. Gorev, S.A. Sokolovsky, and A.I. Sokolovsky, Vìsnik Dnìpropetrovs'kogo unìversitetu. Serîa Fìzika, radìoelektronika, 24(23/2), 83-93 (2016).

[15] S.A. Sokolovsky, A.I. Sokolovsky, I.S. Kravchuk, O.A. Grinishin, Journal of Physics and Electronics, 26(2), 17-28 (2018), https://doi.org/10.15421/331818.

[16] S.A. Sokolovsky, A.I. Sokolovsky, I.S. Kravchuk, O.A. Grinishin, in: Proceedings of IEEE 40 ${ }^{\text {th }}$ International Conference on Electronics and Nanotechnology (ELNANO-2020), ISBN: 978-1-7281-9712-8, (Kyiv, Ukraine, 2020), pp. 284-287.

[17] S.A. Sokolovsky, and A.I. Sokolovsky, in: Proceedings of IEEE 2nd Ukraine Conference on Electrical and Computer Engineering, (UKRCON-2019), ISBN: 978-1-7281-3882-4, (Lviv, Ukraine, 2019), pp. 783-787.

[18] S.A. Sokolovsky, A.I. Sokolovsky, I.S. Kravchuk, and O.A. Grinishin, Journal of Physics and Electronics, 27(2), 29-36 (2019), https://doi.org/10.15421/3919/9.

[19] S.A. Sokolovsky, Theoretical and Mathematical Physics, 168(2), 1150-1164 (2011), https://doi.org/10.1007/s11232-011-0093-z.

\section{ДО РЕЛАКСАЦІЙНИХ ПРОЦЕСІВ У ПОВНО ІОНІЗОВАНІЙ ПЛАЗМІ}

\section{О.Й. Соколовський ${ }^{\mathbf{a}}$ С.О. Соколовський ${ }^{\mathrm{b}}$, О.А. Грінішин ${ }^{\mathrm{a}}$}

а Дніпровський національний університет імені Олеся Гончара, кафедра теоретичної фізики проспект Гагаріна, 72, Дніпро

${ }^{b}$ Придніпровська державна академія будівництва та архітектури, кафедра фізики вул. Чернишевського, 24А, Дніпро

Релаксація густин енергії та імпульсу електронів досліджується в просторово-однорідних станах повністю іонізованої плазми за наявності малого постійного і просторово-однорідного зовнішнього електричного поля. Плазма розглядається в 
узагальненій моделі Лоренца, яка на відміну від стандартної моделі передбачає, що іони утворюють рівноважну систему. Дотримуючись Лоренца, нехтуємо електрон-електронними та іон-іонними взаємодіями. Дослідження засноване на лінійному кінетичному рівнянні, отриманому нами раніше з кінетичного рівняння Ландау. Тому в ньому далекодійна електрон-іонна кулонівська взаємодія описується послідовно. Дослідження моделі грунтується на спектральної теорії оператора інтеграла зіткнень. Цей оператор симетричний і позитивно визначено. Його власні вектори обираємо у вигляді симетричних незвідних тензорів, які описують кінетичні моди системи. Відповідні власні значення є коефіцієнти релаксації і визначають часи релаксації системи. Встановлюється, що скалярні і векторні власні функції описують еволюцію густин енергії та імпульсу електронів (векторну і скалярну моди системи). На цій основі нами виводиться точна система рівнянь для вказаних густин, які справедливі для всіх часів. Далі передбачається, що їх часи релаксації набагато більші часів релаксації всіх інших мод. У цьому випадку існує такий характерний час, що при відповідних великих часах еволюція системи скорочено описується асимптотичними значеннями густин енергії та імпульсу. При скороченому описі функція розподілу електронів залежить від часу тільки через асимптотичні густини і вони задовольняють замкнутій системі рівнянь. У нашій попередній роботі цей результат був доведений за відсутності зовнішнього електричного поля і була знайдена точна нерівноважна функція розподілу. Нами доводиться, що цей скорочений опис має місце і для малого однорідного зовнішнього електричного поля. Це можна розглядати як обгрунтування ідеї функціональної гіпотези Боголюбова для релаксаційних процесів в плазмі. Доказ проводиться в першому наближенні теорії збурень за полем. Однак його ідея правильна у всіх порядках за полем. Рухливість електронів в плазмі, іiі провідність і явище відмінності в рівновазі електронної та іонної температур досліджуються нами в точної теорії і наближено аналізуються. 3 цією метою, слідуючи нашій попередній роботі, обговорюється наближене рішення спектральної задачі методом усіченого розкладання власних функцій в ряди поліномів Соніна. У наближенні одного полінома показується, що нерівноважна функція розподілу електронів в околиці завершення релаксаційних процесів може бути апроксимована функцією розподілу Максвелла. Цей результат є обгрунтуванням припущення Лоренца-Ландау в їх теорії нерівноважних процесів в плазмі. Коефіцієнти релаксації температури і швидкості розраховувалися нами раніше в наближеннях одного і двох поліномів.

КЛЮЧОВІ СЛОВА: плазма, узагальнена модель Лоренца, коефіцієнти релаксації, оператор інтеграла зіткнень, спектральна теорія, наближення одного, полінома, функціональна гіпотеза

\section{К РЕЛАКСАЦИОННЫМ ПРОЦЕССАМ В ПОЛНОСТЬЮ ИОНИЗИРОВАННОЙ ПЛАЗМЕ}

А.Й. Соколовский ${ }^{\mathrm{a}}$, С.А. Соколовский, ${ }^{\mathrm{b}}$ О.А. Гринишин ${ }^{\mathrm{a}}$

аДнепровский национальный университет имени Олеся Гончара, кафедра теоретической физики проспект Гагарина, 72, Днипро

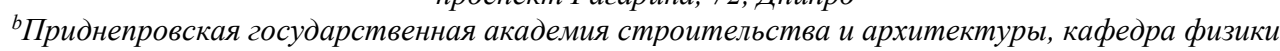
вул. Чернишевського, 24А, Днипро

Релаксация плотностей энергии и импульса электронов исследуется в пространственно- однородных состояниях полностью ионизованной плазмы при наличии малого постоянного и пространственно-однородного внешнего электрического поля. Плазма рассматривается в обобщенной модели Лоренца, которая в отличие от стандартной модели предполагает, что ионы образуют равновесную систему. Следуя Лоренцу, пренебрегаем электрон-электронными и ион-ионными взаимодействиями. Исследование основано на линейном кинетическом уравнении, полученном нами ранее из кинетического уравнения Ландау. Поэтому в нем дальнодействующее электрон-ионное кулоновское взаимодействие описывается последовательно. Исследование модели основывается на спектральной теории оператора интеграла столкновений. Этот оператор симметричен и положительно определен. Его собственные векторы выбираем в виде симметричных неприводимых тензоров, которые описывают кинетические моды системы. Соответствующие собственные значения являются коэффициентами релаксации и определяют времена релаксации системы. Установлено, что скалярные и векторные собственные функции описывают эволюцию плотностей энергии и импульса электронов (векторную и скалярную моды системы). На этой основе нами выводится точная система уравнений для указанных плотностей, справедливая для всех времен. Далее предполагается, что их времена релаксации намного больше, чем времена релаксации всех остальных мод. В этом случае существует такое характерное время, что при соответствующих больших временах эволюция системы сокращенно описывается асимптотическими значениями плотностей. При сокращенном описании функция распределения электронов зависит от времени только через асимптотические плотности, и они удовлетворяют замкнутой системе уравнений. В нашей предыдущей работе этот результат был доказан в отсутствие внешнего электрического поля и была найдена точная неравновесная функция распределения. Здесь доказывается, что это сокращенное описание имеет место и для малого однородного внешнего электрического поля. Это можно рассматривать как обоснование идеи функциональной гипотезы Боголюбова для релаксационных процессов в плазме. Доказательство проводится в первом приближении теории возмущений по полю. Однако его идея верна во всех порядках по полю. Подвижность электронов в плазме, ее проводимость и явление различия в равновесии электронной и ионной температур исследуются нами в точной теории и приближенно анализируются. С этой целью, следуя нашей предыдущей работе, обсуждается приближенное решение спектральной задачи методом усеченного разложения собственных функций в ряды полиномов Сонина. В приближении одного полинома показывается, что неравновесная функция распределения электронов в окрестности завершения релаксационных процессов может быть аппроксимирована функцией распределения Максвелла. Этот результат является обоснованием предположения Лоренца-Ландау в их теории неравновесных процессов в плазме. Коэффициенты релаксации температуры и скорости рассчитывались нами ранее в приближениях одного и двух полиномов.

КЛЮЧЕВЫЕ СЛОВА: плазма, обобщенная модель Лоренца, коэффициенты релаксации, оператор интеграла столкновений, спектральная теория, приближение одного полинома, функциональная гипотеза 